\title{
Severe phenotype in two half-sibs with Adams Oliver syndrome
}

\author{
Rosalba Sevilla-Montoya, M.D. ${ }^{a}$, Braulio Ríos-Flores, M.D. ${ }^{b}$, Elsa Moreno-Verduzco, M.D. ${ }^{c}$, \\ Mauricio Dominguez-Castro, M.D. ${ }^{d}$, Carlos I Rivera-Pedroza, M.D. ${ }^{a}$, Mónica Aguinaga-Ríos, M.D. ${ }^{a}$
}

\begin{abstract}
Adams Oliver syndrome (AOS) is a highly variable entity with terminal transverse limb defects (TTLD) and aplasia cutis congenita (ACC) with a wide phenotypic spectrum. Several inheritance models have been observed; the most severe phenotype has been related to an autosomal recessive (AR) pattern of inheritance.

Objective. To present a family with two half-sibs with a severe phenotype of Adams Oliver syndrome in which the mother was healthy.

Case report. A 27 year-old woman was referred to the Genetics Department. Her previous girl presented acrania, constriction rings and terminal transverse limb defects. The present girl had occipital encephalocele, large scalp defects, aplasia cutis congenita, terminal transverse limb defects and bilateral cleft lip and palate.

We propose that autosomal dominant inheritance with reduced penetrance or gonadal mosaicismhas to be considered in Adams Oliver syndrome with severe intracranial anomalies.

Key words. Adams Oliver, aplasia cutis, terminal transverse limb defect.

http:/ /dx.doi.org/10.5546/aap.2014.eng.e108
\end{abstract}

\section{INTRODUCTION}

In 1945, Adams and Oliver ${ }^{1}$ were the first to describe the combination of cranial aplasia cutis congenita (ACC) with terminal transverse limbs defects (TTLD). Since then, a wide phenotypic spectrum has been reported in these patients.

The ACC is mostly localized at the vertex where it can be associated with different degrees of damage to the periosteum, bone and dura. ${ }^{1}$ Some reports have described the presence of encephalocele ${ }^{2}$ and acrania $^{3}$ as part of a severe form of this syndrome.

Fryns ${ }^{4}$ was the first to describe a probable association between Adams Oliver syndrome

\footnotetext{
a. Genetics Department.

b. Neurology Department.

c. Pathology Department.

Instituto Nacional de Perinatología, Mexico City, Mexico.

E-mail address:

Mónica Aguinaga-Ríos, M.D: aguinagamonica09@gmail.com

Conflict of Interest: None.
}

Received: 10-28-2013

Accepted: 2-10-2014
(AOS) with structural intracranial anomalies. It has been proposed that $32 \%$ of patients with autosomal recessive inheritance present a severe neurological phenotype with microcephaly, mental retardation and intracranial anomalies. ${ }^{5}$ However, these anomalies are also seen in cases with an apparent autosomal dominant inheritance. ${ }^{2,6}$

The purpose of this paper is to report two half-sibs with severe Adams Oliver syndrome with the finding of an amniotic band attached to the placenta, to list possible etiologies and the inheritance patterns of this syndrome.

\section{Case report}

A 27 year old woman G5, C2,A2, was referred to the Genetics Department at 16 weeks of gestation with an ultrasound that reported fetal hydrocephaly. She had the history of two spontaneous first trimester miscarriages with her first partner;an apparently healthy son who had a sudden death without an apparent cause at the age of 1 year 8 months and a female stillbirth from her second partner. That girl showed acrania and constriction rings with distal transversal limb defects of the left $4^{\text {th }}$ and $5^{\text {th }}$ finger; a clinical diagnosis of amniotic band syndrome was given at that time. The pathology report revealed meroacrania, amputation of the fifth finger of the left hand, complete left eye and partial right exophthalmos. Our proband is the daughter of the mother's third partner; a healthy 26 years- old who had two healthy children with another partner.The mother and father were completely healthy. Both have normal chromosomes. There was no history of maternal drug abuse or infections during pregnancy.

Prenatal structural ultrasound at 25 weeks reported macrocraneum with asymmetric ventriculomegaly, occipital encephalocele and bilateral cleft lip. Prenatal karyotype was normal $46, X X$. She was born at 41 weeks of gestation;her birth weight was $4570 \mathrm{~g}$ (above $97^{\text {th }}$ centile), length $53 \mathrm{~cm}$ (centile 90) and OFC: $51 \mathrm{~cm}$ (above 99 th centile). A large scalp defect was noticed involving the frontal and occipital areas with an apparent occipital encephalocele; aplasia 
cutis was evident in the vertex region, her hands showed absence of the distal $4^{\text {th }}$ right finger phalange and hypoplasia of the distal phalange and nail of the $3^{\text {th }}$ right finger and an apparent constriction ring (Figure 1). Her face had sparse eyebrows, hypoplasia of the right eyelid with an upper coloboma. There was absence of the tarsal and orbicular muscles in the right eye and an ulcerated corneal lesion was observed; midfacial hypoplasia with bilateral cleft lip and palate was also noticed. She had left talipes equinovarus and a normal right foot. Computed axial tomography showed plagiocephaly with absence of parietal and medial cerebral tissue; the cerebral cortex showed severe cortical dysplasia and was displaced anteriorly. A severe medial bone defect in the frontal and occipital areas was present and a cystic dilatation of the posterior fossa with occipital encephalocele was observed (Figure 2).

An echocardiogram showed a patent ductus arteriosus. Renal ultrasound was normal.

The placenta was hypertrophic (730 grams) and showed a fibrous band of $9 \times 1.2 \mathrm{~cm}$ attached to the border with no loose strands (Figure 3).

Based on the presence of ACC and TTLD the diagnosis of AOS was made. The mother had no scalp or limb defects. Her radiologic study showed normal skull and fingers.

\section{DISCUSSION}

We report two half-sibs with a severe form of Adams Oliver syndrome in which the mother had no clinical evidence of the disease. Clinical history suggests autosomal dominant inheritance, but we cannot rule out gonadal mosaicism.

Savarirayan, et al. ${ }^{6}$ were the first to suggest maternal gonadal mosaicism in a family with two affected sibs and a $5^{\text {th }}$ finger nail hypoplasia in the mother. They reported severe cortical dysplasia in one patient and constriction rings in both sibs. The patient reported in our study present severe intracranial defects characterized by a severe cortical dysplasia of various cerebral regions. These anomalies represent early disturbances in migration and cellular differentiation. Our case further supports the presence of severe intracranial anomalies in this form of inheritance. Southgate, et al. ${ }^{7}$ reported two families with autosomal dominant inheritance, however in this paper we report a healthy mother with two severely affected half sibs, both with healthy fathers.

Hoyme, et al. ${ }^{8}$ hypothesized that in utero vascular thrombotic accidents might led to
Figure 1. a) Aplasia cutis in the vertex. b) Absence of the distal 4th right finger phalange. c) Hypoplasia of the distal phalange and nail of the $3 \mathrm{rd}$ right finger and an apparent constriction ring

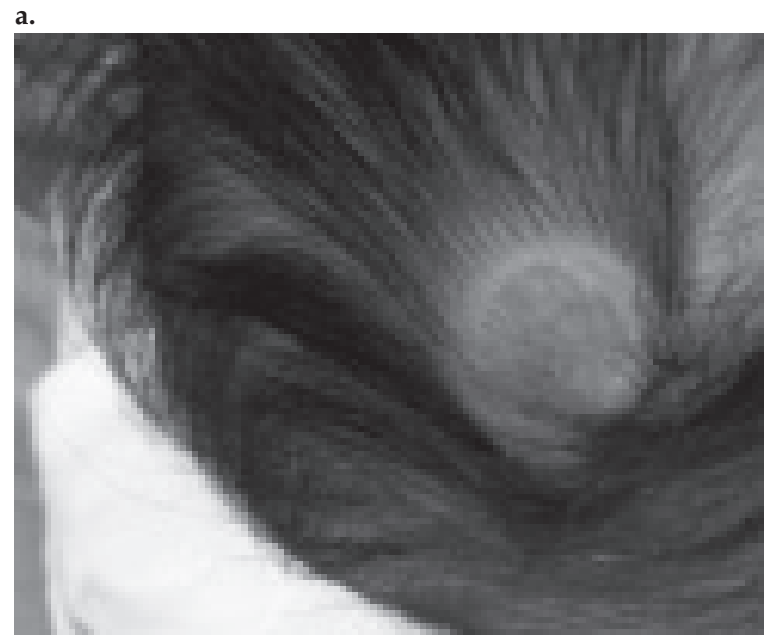

b.

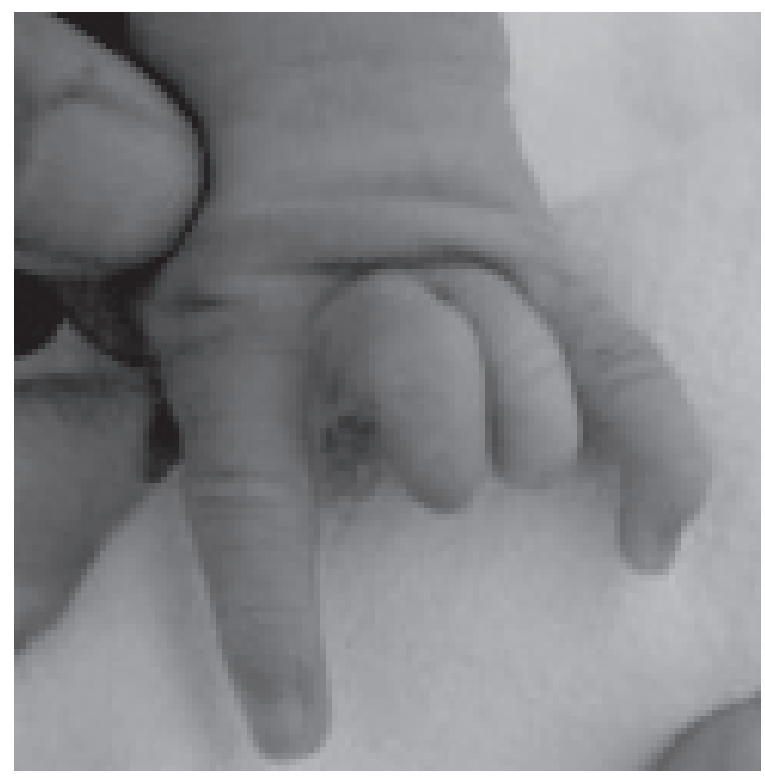

c.

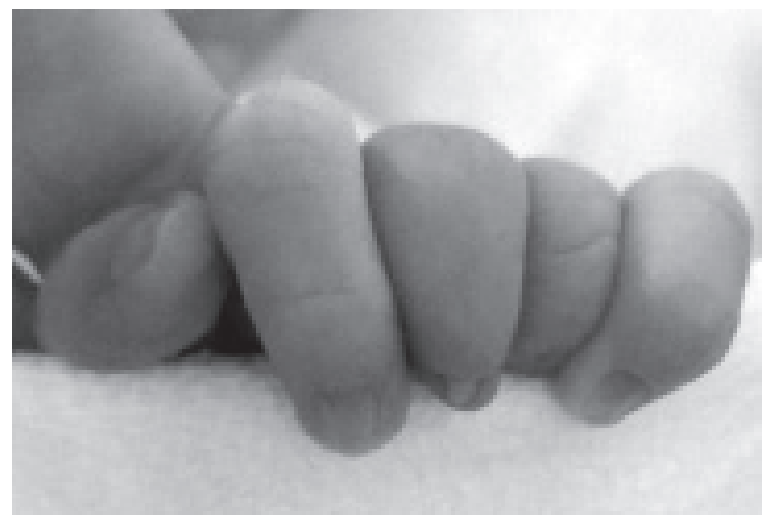


interruption of blood supply to the developing structures.

The main etiology and pathogenesis of this syndrome remains controversial. Molecular analysis of patients affected by this condition, in an autosomal dominant pattern, reveled mutations in two genes; ARHGAP31 and RBPJ; known to regulate members of the Rho GTPase family. Some mutations in ARHGAP31 result in a constitutive activation of this gen that leads to an absence of active Cdc42, originating cytosqueletal actin anomalies; these have been found in autosomal dominant cases. ${ }^{7}$ This suggests a relation between the presence of mesenquimal anomalies and fetal anatomy damage. Hassed studied the Notch pathway mediated by RPBJ in two unrelated patients and found two mutations in this transcriptional regulator, essential for mesenchimal cell proliferation and skeletal development, ${ }^{9}$ also important for the epidermis, follicular structure ${ }^{10}$ and vascular components. ${ }^{11}$

In the case reports of families with a recessive inheritance Shasheen, et al., found mutations in DOCK $6^{12}$ and recently this same group found mutations in the gen EOGT, responsible of the glycosylation of extracellular proteins no related to the cytoskeleton in patients with AOS. This may explain the wide phenotypic variability of these recessive cases. ${ }^{13}$

Our patient had a previous stillbirth with acrania and the present case with encephalocele. These anomalies may reflect severe ossification bone defects as suggested by Kuster, et al. ${ }^{2}$ and reported by Farrell, et al. ${ }^{14}$ who referred that $27 \%$ of patients with AOS had a skull defect. In these cases, the clinical diagnosis may be difficult since ACC cannot be seen. Chitayat, et al. ${ }^{3}$ were the first to describe a patient with acrania, TTLD

FIGURE 2. CT: medial bone defect (DC), midfacial hypoplasia, bilateral cleft palate. Plagiocephaly with cerebral cortex anteriorly displaced (arrow). Occipital encephalocele (E). Left lateral ventricule (VI)
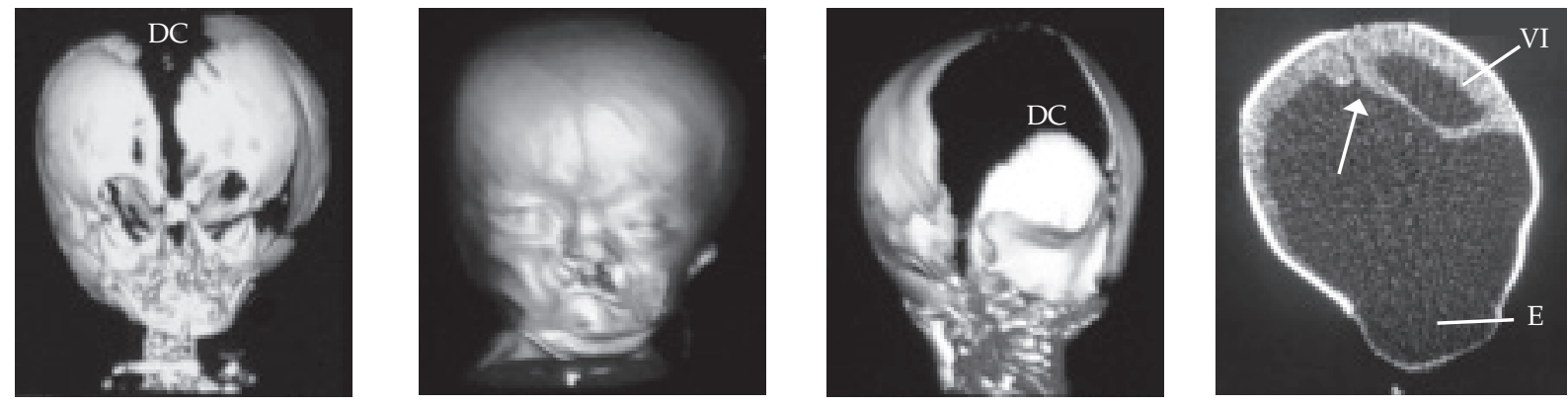

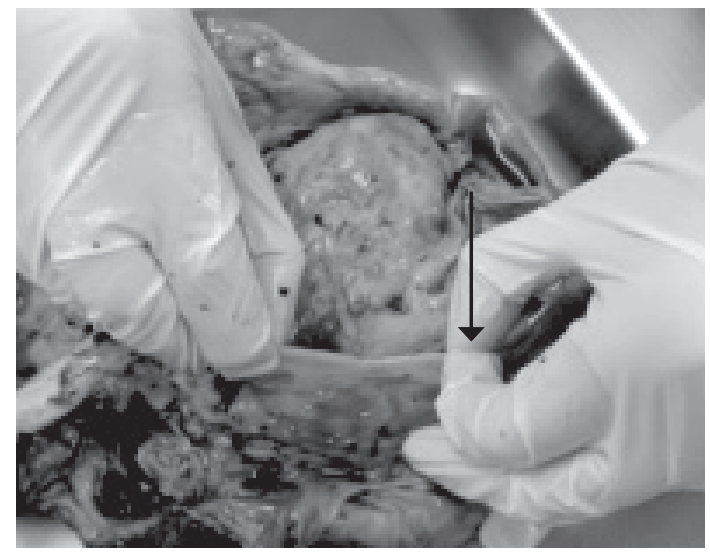

b.

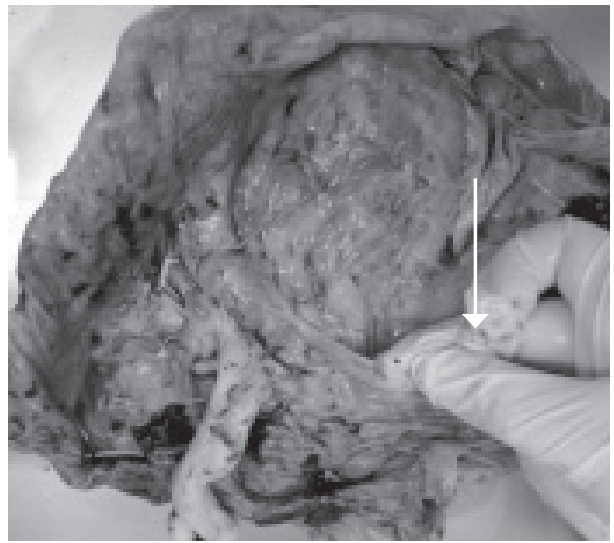


and cutaneous lesions; they concluded that this phenotype may represent a severe form of AOS and suggested the intentional search of TTLD in patients with anencephaly. Our patient's studies showed a wide ossification cranial defect that may be considered as part of AOS when found in addition to a TTLD.

A clinical diagnosis of amniotic band syndrome was made in the patient's first child. This syndrome is a common defect with limb reduction, and different etiology theories. Streeter ${ }^{15}$ suggests in his intrinsic theory that the fibrous bands and fetal malformations have a common etiology in early embriologic stages due to alterations of the germinal discs; that's why we propose that this two may not be independent anomalies. The presence of constriction rings in several patients ${ }^{6}$ with AOS, may support this idea.

Therefore, a careful examination of the placenta must be done in all patients with constriction rings and terminal transverse limb defects.

Diagnosis in our patient was made based in the presence of ACC and TTLD; she did not present any lower limb defects which have been referred in $78 \%$ of patients. ${ }^{14}$ She had bilateral cleft lip and palate; this anomaly is a rare finding reported in some patients. ${ }^{14}$

AOS molecular studies have shown genetic heterogeneity. Mutations in ARHGAP31 and RBPJ may be responsible for the severe phenotype observed in our case. Autosomal recessive inheritance is unlikely since the fathers are different and unrelated. Germ line mosaicism cannot be ruled out. Samples of our family were kindly accepted by Dr.Trembath to perform molecular analysis. The gain of function panel mutations of the ARHGAP31gen was reported negative, and the search of other candidate's genes is still in progress. The research in this and other genes involved in AOS may help us to understand the physiopathology and clinical variability of this disease.

\section{Acknowledgements:}

To Dr. Richard C. Trembath, and the Department of Medical \& Molecular Genetics King's College London School of Medicine for receiving the families samples to performthe molecular analysis of AOS.

\section{REFERENCES}

1. Adams FH, Oliver CP. Hereditary deformities in man due to arrested development. J Hered 1945; 36:3-7.

2. Küster W, Lenz W, Kääriäinen H, Majewski F. Congenital scalp defects with distal limb anomalies (Adams-Oliver syndrome): report of ten cases and review of the literature. Am J Med Genet 1988; 31(1):99-115.

3. Chitayat D, Meunier C, Hodgkinson K, Robb L, Azouz M. Acrania: A Manifestation of the Adams-Oliver Syndrome. Am J Med Genet 1992; 44(5):562-6.

4. Fryns JP. Congenital scalp defects with distal limb reduction anomalies. J Med Genet 1987; 24(8):493-6.

5. Temtamy SA, Aglan MS, Ashour AM, Zaki MS. AdamsOliver syndrome: Further evidence of an autosomal recessive variant. Clin Dysmorphol 2007;16(3):141-9.

6. Savarirayan R, Thompson EM, Abbott KJ, Moore MH. Cerebralcortical dysplasia and digital constriction rings in Adams-Oliver syndrome. Am J Med Genet 1999; 86(1):15-9.

7. Southgate L, Machado R, Snape K, Primeau M, et al. Gainof-Function Mutations of ARHGAP31, a Cdc42/Rac1 GTPase Regulator, cause Syndromic Cutis Aplasia and Limb Anomalies. Am J Hum Genet 2011;88(5):574-85.

8. Hoyme HE, Jones KL, Van Allen MI, Saunders BS, Benirschke K. Vascular pathogenesis of transverse limb reduction defects. J Pediatr 1982;101(5):839-43.

9. Hassed SJ, Wiley G, Wang S, Lee J, et al. RBPJ Mutations Identified in Two Families Affected by Adams-Oliver Syndrome. Am J Hum Genet 2012; 91(2):391-5.

10. Vauclair S, Nicolas M, Barrandon Y, Radtke F. Notch1 is essential for postnatal hair follicle development and homeostasis. Dev Biol 2005;284(1):184-93.

11. Dou GR, Wang Y,Hu X, Hu L, et al. RBP-J, the transcription factor downstream of Notch receptors, is essential for the maintenance of vascular homeostasis in adult mice. FASEB J 2008;22(5):1606-17.

12. Shaheen R, Fageih E, Sunker A, Morsy H, et al. Recessive Mutations in DOCK6, Encoding the Guanidine Nucleotide Exchange Factor DOCK6, Lead to Abnormal Actin Cytoskeleton Organization and Adams-Oliver Syndrome. Am J Hum Genet 2011;89(2):328-33.

13. Shaheen R, Aglan M, Keppler-Noreuil K, Fageih E, et al. Mutations in EOGT confirm the genetic heterogeneity of autosomal-recessive Adams Oliver syndrome. Am J Hum Genet 2013;92(4): 598-604.

14. Farrell SA, Warda LJ, LaFlair P, Szymonowicz. Adams-Oliver syndrome: A case with juvenile chronic myelogenous leukemia and chylothorax. Am J Med Genet 1993;47(8):1175-9.

15. Streeter GL. Focal deficiencies in fetal tissues and their relation to intrauterine amputation. Contrib Embryol Carnegie Inst 1930;22:1-44. 